\title{
Esquistosomiasis: una enfermedad importada
}

\author{
L. Ramos Macías ${ }^{\mathrm{a}}$, I. Sebastián García ${ }^{\mathrm{a}}$, R. Alcuaz Romanob, \\ M. Jiménez Toledo a B. Santana Salcedo \\ aDepartamento de Pediatría. Complejo Hospitalario Insular Materno-Infantil de Canarias. \\ Las Palmas de Gran Canaria, Las Palmas. España. \\ bServicio de Microbiología. Hospital Universitario de Gran Canaria Dr. Juan Negrín. \\ Las Palmas de Gran Canaria, Las Palmas. España.
}

\begin{abstract}
Resumen
Las enfermedades infecciosas causan más del 50\% de las muertes en edad infantil.

La Organización Mundial de la Salud ha señalado la esquistosomiasis como una importante causa de morbilidad en los países tropicales. La inmigración y los viajes internacionales han contribuido a la aparición en nuestro país de las denominadas enfermedades importadas. Los pediatras debemos conocer la distribución geográfica así como la clínica más frecuente de estas enfermedades. Una buena historia epidemiológica que recoja país de procedencia, duración de la estancia y factores de riesgo nos orientará en el diagnóstico. Presentamos dos casos clínicos de pacientes procedentes de países tropicales diagnosticados de esquistosomiasis. Uno de ellos llega a nuestro medio a través de un proceso de adopción internacional y el segundo como inmigrante.
\end{abstract}

Palabras clave: Esquistosomiasis. Enfermedades parasitarias. Inmigración.

\section{Schistosomiasis: an imported disease}

\section{Abstract}

Infectious diseases cause more than fifty per cent of deaths in childhood. The World Health Organization has pointed out schistosomiasis as a major cause of morbidity in tropical countries. Immigration and international travels have contributed to the occurrence in our country of so-called imported diseases. Pediatricians should know the geographical distribution as well as the most frequent clinical manifestations of these diseases. A good epidemiological history collecting country of origin, time of stay and risk factors can advise to a diagnosis. We present two clinical cases of patients arriving from tropical countries diagnosed of schistosomiasis. One of them comes in a process of international adoption and the second as immigrant.

Key words: Schistosomiasis. Parasitic diseases. Immigration.

Leticia Ramos Macías: Iramosmacias@gmail.com

Los autores declaran no presentar conflictos de intereses en relación con la preparación y publicación de este artículo. 


\section{Introducción}

En el mundo, más de 250 millones de personas padecen bilharziasis ${ }^{1}$, de hecho se trata de la segunda parasitosis más frecuente en el hombre tras el paludismo². Entre los gusanos planos, son con mayor probabilidad los esquistosomas los que ocasionan mayor morbilidad y mortalidad. Las principales especies de esquistosomas que parasitan al hombre son $S$. haematobium (figura 1), S. mansoni (figura 2) y $S$. japonicum. Mientras los dos últimos pueden tener otros hospedadores, S. haematobium sólo se encuentra en humanos.
Las zonas endémicas son, para $S$. mansoni: África continental, Madagascar, India, Surinam, Venezuela y Brasil, y para S. haematobium: África, Oriente Medio, India y Portugal.

El hombre es el huésped definitivo y adquiere la infección a través de la piel en agua dulce contaminada. Los adultos de S. mansoni viven en las venas mesentéricas; los de S. haematobium en las venas de la vejiga, próstata y plexo uterino. La puesta de huevos se realiza en las vénulas de intestino y recto (S. mansoni) o en las de la vejiga (S. haematobium). Los huevos emigran de los pequeños vasos al tubo digestivo ( $S$.

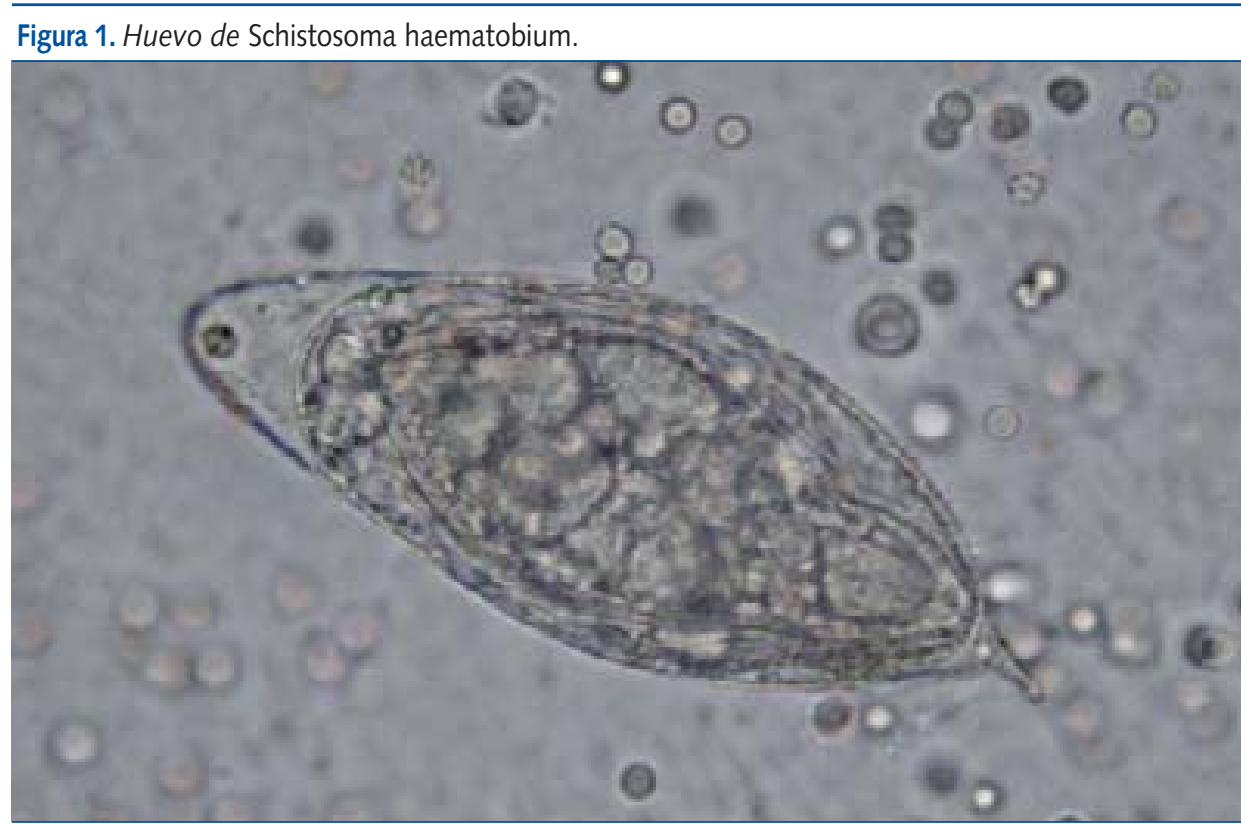

Cortesía de: Servicio de Microbiología, Hospital Universitario Doctor Negrín. Las Palmas de Gran Canaria. 
mansoni) o a la vejiga (S. haematobium) para poder ser eliminados por las heces o por la orina.

\section{Casos clínicos}

\section{Caso n. ${ }^{0} 1$}

Niña de diez años, procedente de Etiopía, que es remitida para estudio de enfermedades infecciosas. Lleva cuatro meses viviendo en España y está asintomática. Refiere haberse bañado en un río reiteradas veces con anterioridad. Los antecedentes personales son desconocidos; refiere estar sana.
La exploración física es normal con un peso de $39 \mathrm{~kg}$ (P90), talla $149 \mathrm{~cm}$ (P97) y tensión arterial 100/60 mm Hg.

Los análisis de laboratorio muestran una marcada eosinofilia con recuento de 907 eosinófilos/ $\mu \mathrm{L}$. La bioquímica realizada fue normal, y en la ecografía abdominal no se demostraron hallazgos significativos.

Los estudios microbiológicos mostraron una gota gruesa, así como detección de antígeno de Plasmodium sp., negativos; serología negativa para $\mathrm{VIH}$ y virus de la hepatitis $A, B$ y C; investigación negativa de Schistosoma en orina.

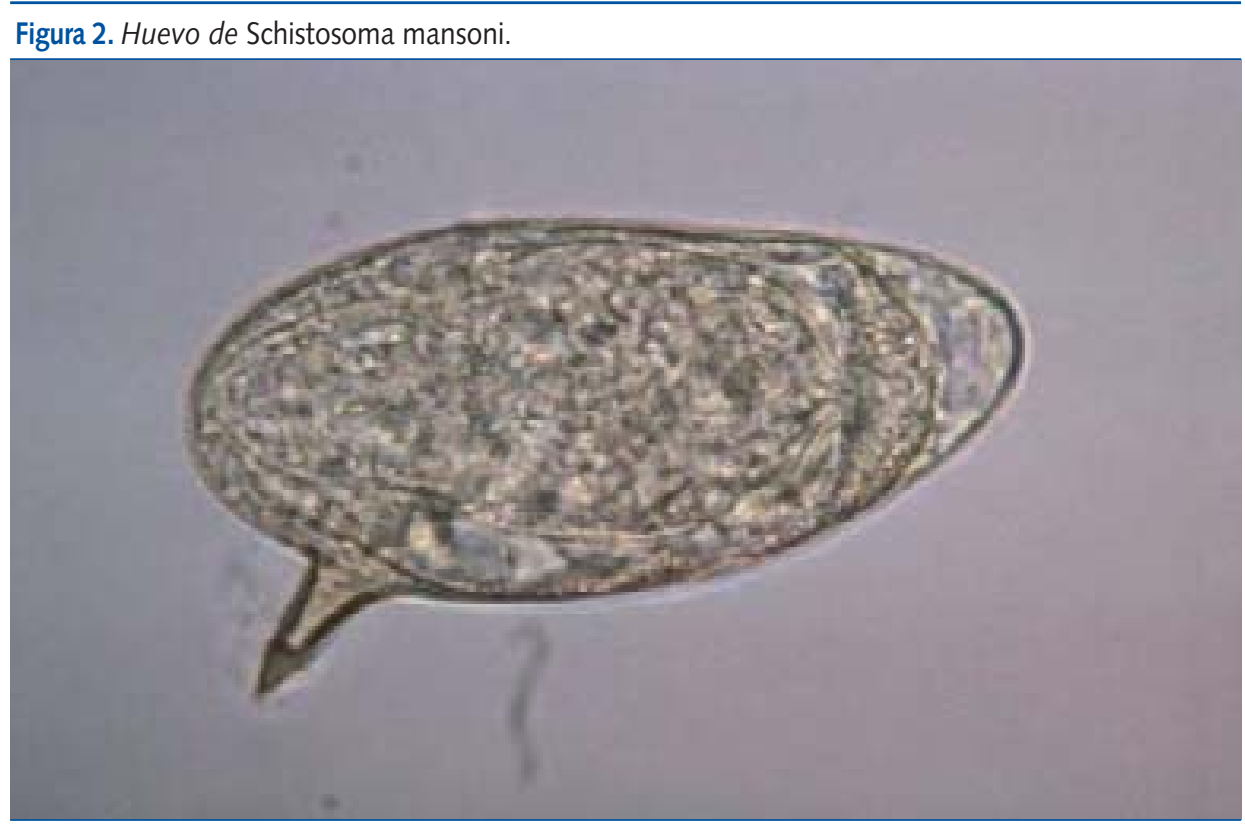

Cortesía de: Servicio de Microbiología, Hospital Universitario Doctor Negrín. Las Palmas de Gran Canaria. 
En la investigación de parásitos intestinales se observan huevos de Schistosoma mansoni, Hymenolepis nana y Enterobius vermicularis, así como quistes de Entamoeba histolytica/dispar y Blastocystis hominis.

Se procedió a tratamiento con praziquantel, metronidazol y mebendazol con buena evolución clínica posterior; la investigación de parásitos intestinales fue negativa, con normalización de los niveles de eosinófilos a los dos meses postratamiento.

\section{Caso n. ${ }^{\circ} 2$}

Niño de ocho años procedente del África subsahariana, que acude para estudio de hematuria macroscópica al final de la micción y proteinuria de más de un año de evolución. Lleva dos años viviendo en nuestra comunidad. Refiere baños anteriores frecuentes en río. No tiene antecedentes personales ni familiares a destacar. La exploración física fue normal.

Los análisis de laboratorio muestran un hemograma con anemia microcítica, con $\mathrm{Hb} 10,9 \mathrm{~g} / \mathrm{dL}$, Hto $32,8 \%$, VCM $74,9 \mathrm{fL}$ y eosinofilia con 767 eosinófilos/ $\mathrm{LL}$; VSG $40 \mathrm{~mm} / \mathrm{h}$. La bioquímica muestra urea y creatinina e iones normales. Estudio inmunológico con niveles de inmunoglobulinas y complemento dentro de la normalidad. El sistemáti- co de orina muestra hematuria microscópica y presencia de cristales de oxalato cálcico.

La ecografía abdominal fue informada como hidronefrosis grado II de pelvis renal izquierda.

La investigación de Schistosoma sp. en orina fue positiva visualizándose huevos de S. haematobium. El coprocultivo fue negativo. Las serologías para Plasmodium falciparum, Entamoeba histolytica, Schistosoma sp., y virus de las hepatitis A, B y C fueron negativas.

El tratamiento se realizó mediante dos dosis de praziquantel a $20 \mathrm{mg} / \mathrm{kg} /$ dosis separadas por 12 horas. El paciente no acudió a posteriores revisiones.

\section{Discusión}

Actualmente, la cuarta parte de la población mundial está infectada por algún tipo de helminto, constituyendo la esquistosomiasis un importante problema de salud en los países en vías de desarrollo ${ }^{3}$.

La población inmigrante en España está en aumento en los últimos años; en el año 2007, con más de cuatro millones y medio de personas, constituye el $12,2 \%$ de la población española; la cifra del Instituto Nacional de Estadística de 2000 para este grupo poblacional era $2,7 \%{ }^{4}$. Más del $50 \%$ de la población in- 
migrante en 2007 procede de lugares de alta prevalencia para estas enfermedades: $39 \%$ de América Latina y $14 \%$ de África subsahariana ${ }^{4}$.

La ausencia de hospedadores intermedios adecuados sumada a las buenas condiciones sanitarias hacen casi imposible la infección en nuestro medio, con un riesgo de transmisión a la población nulo. El interés en la sospecha diagnóstica y posible tratamiento de estas enfermedades afecta a la población inmigrante.

Las infecciones por esquistosoma pueden persistir muchos años en el hospedador humano. La edad de mayor incidencia para infectarse es la preadolescencia, siendo más frecuentes en los varones que en las mujeres.

La clínica producida depende de la fase de la enfermedad y del tipo de esquistosoma que parasite al individuo. En general, las manifestaciones de la enfermedad son clínicamente importantes en una pequeña proporción de las personas infectadas por los esquistosomas intestinales. Por el contrario, la esquistosomiasis urinaria provoca síntomas en la mayoría de las personas infectadas 5 .

Las manifestaciones clínicas de esta parasitosis cambian según la fase del ciclo de infestación. En la zona de penetración de la larvas aparece una dermatitis por cercarias. Puede aparecer con cualquiera de los tipos de esquistosoma. Se produce, a las 48 horas del contacto, una erupción maculopapular que se acompaña de prurito y fiebre que desaparece en pocos días. En ambos casos presentados se refiere el contacto con aguas dulces en zonas endémicas para esta infestación.

En la fase de invasión o migración de las larvas, la clínica responde a la puesta de huevos y formación de antígenos solubles. Es característica del S. mansoni y puede durar unos 3 meses. Se presenta como una fibrosis periportal, hipertensión portal y hepatoesplenomegalia con fiebre alta, fatiga, urticaria, linfadenopatía y eosinofilia. Puede haber dolor abdominal, pérdida de peso y diarrea. Se denomina fiebre de Katayama y ya está presente la eosinofilia ${ }^{5}$. Esta se considera como la presencia en sangre periférica de un número de eosinófilos mayor de $450 / \mu \mathrm{L}$. La presencia de una eosinofilia importada obedece casi en su totalidad a una infección por helmintos ${ }^{6}$. Igualmente, un mismo paciente puede presentar varias parasitosis ${ }^{6-8}$, como sucedió en nuestra primera paciente. Nuestros dos pacientes presentaron una eosinofilia que facilitó la sospecha diagnóstica.

Meses o años tras el inicio de la parasitación se pueden producir reacciones granulomatosas y fibrosis en los órganos 
afectados; en el tracto gastrointestinal cuadros leves con epigastralgia y diarrea, hasta pólipos crónicos, diarrea sanguinolenta, hematemesis y esplenomegalia. En el tracto urogenital el $S$. haematobium se asocia con hematuria, polaquiuria, dolor suprapúbico y hasta engrosamiento de la pared vesical, hidrouréter o hidronefrosis. Se han descrito casos de neuroesquistosomiasis. Se ha demostrado una asociación entre carcinoma epidermoide de vejiga y $S$. haematobium ${ }^{5,8}$.

El diagnóstico parasitológico directo se realiza mediante la búsqueda de huevos en heces u orina. La serología requiere un periodo de seis semanas para su positivización. Las pruebas de imagen (eco- grafía, urografía, etc.) son de gran utilidad. En caso de esquistosomiasis digestivas pueden ser útiles la biopsia rectal o hepática y la colonoscopia ${ }^{5}$.

El tratamiento de elección es el praziquantel en dosis de 40-60 mg/kg dividido en dos únicas dosis separadas por 12 horas?.

Como conclusión: las esquistosomiasis son enfermedades de relativo fácil diagnóstico. Los movimientos poblacionales hacen necesaria una detallada anamnesis epidemiológica en la búsqueda de infecciones importadas. Dada la alta incidencia de portadores aparentemente sanos recomendamos estudio de la población procedente de zonas endémicas.

\section{Bibliografía}

1. Gairi Burgués MA, Bosch Muñoz J, Llusá Parramon A, Gomá AR. Schistosoma haematobium como causa de hematuria. An Esp Pediatr. 2002;56:368-9.

2. Maese Heredia R, Rubí Palomares I, Peña Muñoz M, Bueno Fernández A, Weil Lara B. Hematuria recurrente. An Esp Pediatr. 2002;57: 501-2.

3. Pardo J, Pérez-Arellano JL, Galindo I, Belhassen $M$, Cordero $M$, Muro A. Diagnóstico de helmintiasis importadas. Enferm Infecc Microbiol Clin. 2007;25:329-35.

4. Instituto Nacional de Estadística. Encuesta Nacional de Inmigrantes 2007. [Consultado el

13/01/2010]. Disponible en www.ine.es/ineb menu/mnu_migrac.htm

5. Corachán $M$. Esquistosomiasis o bilharziosis importada. JANO. 2003;64:36-41.

6. Pérez-Arellano JL, Muro-Álvarez A. Conducta diagnóstica y terapéutica ante una eosinofilia importada. JANO. 2006;67:35-9.

7. Ramos L, Poch J, Pérez-Arellano JL, Alcuaz Romano R, Rial González R. Infección parasitaria múltiple importada en una paciente pediátrica: patología del niño inmigrante. Acta Pediatr Esp. 2007;65:79-81.

8. Bichler KH, Savatovsky I, Naber KG, Bischop MC, Bjerklund-Johansen TE, Botto H. EAU guidelines for the management of urogenital schistosomiasis. Eur Urol. 2006;49:998-1003. 